\title{
O LEMA APRENDER A APRENDER NA LITERATURA DE INFORMÁTICA EDUCATIVA
}

\author{
Benedito de Jesus Pinheiro Ferreira* \\ NEWTON DUARTE**
}

\begin{abstract}
RESUMO: Este artigo faz uma análise das concepções pedagógicas presentes na literatura nacional de informática educativa, assim como na obra de Seymour Papert, dada a influência incontestável desse autor na referida literatura. Identificamos nesse campo uma forte hegemonia das pedagogias do aprender a aprender, pela via do construtivismo, do construcionismo, dos projetos de aprendizagem e da pedagogia das competências, entre outros. Fazemos uma análise crítica dessas tendências à luz da pedagogia históricocrítica, apontando um conjunto de aspectos que carecem de análise aprofundada, com destaque para a problemática contraposição entre ensino e aprendizagem.

Palavras-chave: Informática educativa. Aprender a aprender. Pedagogia histórico-crítica.
\end{abstract}

\section{THE SLOGAN LEARNING TO LEARN IN THE EDUCATIONAL INFORMATICS LITERATURE}

ABSTRACT: This paper makes a characterization of pedagogical conceptions found in the educational informatics literature in Brazil as well as in the work of Seymour Papert given the undeniable influence of this author in that literature. We identified a strong hegemony in this field of learning-to-learn pedagogy by means of constructivism, constructionism, learning projects and pedagogy of competencies among others. We make a critical analysis of these trends in light of the historical-critical pedagogy pointing to a number of aspects that need further discussion, highlighting the problematic opposition between teaching and learning.

Key words: Educational informatics. Learning to learn. Historical-critical pedagogy.

\footnotetext{
* Doutor em Engenharia de Sistemas e Computação e professor da Faculdade de Computação da Universidade Federal do Pará (UFPA). E-mail: ferreira@ufpa.br

* Doutor em Educação e professor do Departamento de Psicologia da Educação da Universidade Estadual Paulista "Júlio de Mesquita Filho" (Unesp). E-mail: newton.duarte@uol.com.br
} 


\title{
LE SLOGAN APPRENDRE À APPRENDRE DANS LA LITTÉRATURE DE L'INFORMATIQUE ÉDUCATIVE
}

\begin{abstract}
RÉSUMÉ: Cet article constitue une analyse des conceptions pédagogiques dans la littérature nationale de l'informatique éducative, ainsi que du travail de Seymour Papert, compte tenu de l'influence incontestable de l'auteur dans cette littérature. Nous avons identifié dans ce domaine une hégémonie forte de la pédagogie de l'apprendre à apprendre, à travers, parmi d'autres: le constructivisme, le constructionnisme, le projet d'apprentissage et les pédagogies des compétences. Nous faisons une analyse critique de ces tendances à la lumière de la pédagogie historique-critique mettant en évidence un certain nombre d'aspects qui méritent d'être approfondis, ceci en soulignant l'opposition problématique entre enseignement et apprentissage.
\end{abstract}

Mots-clés: Informatique éducative. Apprendre à apprendre. Pédagogie historique-critique.

\section{Introdução}

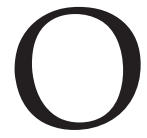

tema das relações entre a informática e a educação pode ser abordado por vários ângulos, desde as discussões sobre o uso das tecnologias de informação e comunicação (TICs) na escola até a criação de outros espaços educativos pela assim chamada "cultural digital". A área de estudos que ficou conhecida como informática educativa (IE) congrega distintas perspectivas e referências teóricas. Assim, por exemplo, Seymour Papert é uma das importantes referências nessa área, não havendo, entretanto, consenso em torno de suas ideias sobre as relações entre informática e educação. Contudo, as divergências que existam em relação a determinados temas no interior da informática educativa não têm abalado um consenso fortemente estabelecido em torno ao lema pedagógico aprender a aprender. Variantes desse lema, como construtivismo, construcionismo, projetos de aprendizagem, pedagogia das habilidades e competências, têm notável frequência nessa literatura. Verifica-se a quase completa ausência de orientação pedagógica distinta, o que caracteriza a forte hegemonia dessa tendência.

Cabe inicialmente uma observação acerca dos termos construtivismo e construcionismo. O primeiro remete à corrente pedagógica que tem como principal referência a epistemologia genética de Jean Piaget e defende que o conhecimento é construído pelo sujeito no processo de interação com o objeto cognoscível. O segundo é um neologismo decorrente de uma transposição para o português do termo em inglês constructionism, assim sintetizado por Papert (1980, parte 1): "dando-se às crianças boas coisas para se fazer elas poderão 'aprender fazendo' muito melhor do que [aprendiam] antes". É explícita a adoção do "aprender fazendo", oriundo da pedagogia de John Dewey, relacionado ao princípio da educação funcional defendida 
por Claparéde. Portanto, construcionismo significaria o processo pelo qual o sujeito adquire um conhecimento, usando-o para "construir" algo:

Temos tentado encontrar maneiras pelas quais crianças possam usar a matemática para fazer algo interessante, de tal forma que a relação das crianças com a matemática seja mais parecida com a dos engenheiros, dos cientistas, dos banqueiros e de todas as pessoas importantes que usam a matemática construtivamente para construir algo. (Papert, 1980, parte 1)

Papert opõe o construcionismo ao que ele chama de instrucionismo (instrucionism, no original). Diferentemente do construcionismo (centrado na aprendizagem), o instrucionismo estaria centrado na tentativa de melhorar o ensino e, no que se refere ao uso dos computadores na educação, poderia ser assim sintetizado: "Para obtermos uma educação melhor precisamos melhorar o ensino. Passando a usar os computadores faremos com que eles ensinem" (idem, ibid.).

A despeito das nuanças que distinguem construcionismo e construtivismo, bem como das especificidades da pedagogia dos projetos e da pedagogia das competências, essas abordagens podem ser reunidas sob a denominação de "pedagogias do aprender a aprender" (Duarte, 2001), por partilharem a contraposição entre ensino e aprendizagem; por serem "concepções negativas sobre o ato de ensinar" (Duarte, 1998, página).

Para efeito de polêmica com outras correntes pedagógicas e de consideração das possibilidades alternativas, o aprender a aprender normalmente é confrontado com o que se denomina ensino tradicional ou instrucionismo, com a proclamação do primeiro como o mais afinado a uma prática educacional democrática, incompatível esta com o ensino tradicional (Valente, 1995; Valente \& Almeida, 1997; Fagundes, Sato \& Maçada, 1999).

A indicação de prática pedagógica que decorre dessa orientação do aprender a aprender é o de que à escola caberá assegurar condições ao aluno para realizar autonomamente seu aprendizado, e não ser ensinado ou colocado no polo receptivo de uma transmissão de conhecimentos, tida em geral como contrária à aprendizagem.

Assim, o objetivo deste estudo é contribuir para o enriquecimento do debate sobre as concepções pedagógicas presentes na literatura de IE, suscitando um questionamento sobre a orientação hegemônica do aprender a aprender, seus pressupostos e a prática docente resultante dela. Alguns aspectos desse debate são: a transmissão se contrapõe à aprendizagem? Que lições históricas podem ser apropriadas para a superação da escolha entre instrucionismo ou construtivismo? Quais as consequências da adoção do aprender a aprender como orientação pedagógica das práticas de IE? 
A referência teórica deste estudo é a pedagogia histórico-crítica (Saviani, 2005, 2007, 2008a, 2008b). Esta pedagogia, além de ter o mérito de analisar a educação a partir de um posicionamento crítico em relação aos profundos problemas com que se depara a sociedade contemporânea, pode ainda contribuir especificamente para a análise das possibilidades e limites do uso da informática na educação. A valorização da historicidade, própria dessa pedagogia, possui desdobramentos analíticos importantes: a) a compreensão da relação dialética entre a construção histórica da cultura e a formação dos indivíduos; b) a consideração das possibilidades dos caminhos pedagógicos, não de forma idealista, mas em confronto com as experiências históricas.

\section{A contraposição entre ensino e aprendizagem na literatura da infor- mática educativa}

Seymour Papert, pesquisador influente na comunidade nacional de informática educativa, participou, em 1995, de debate com o educador Paulo Freire. Nesse debate (Freire \& Papert, 1995; Papert, 2000), Papert, a partir de sua compreensão de que há na escola um desequilíbrio entre ensino e aprendizado, com improdutiva predominância do primeiro, explicita o que ele denomina de três estágios da aprendizagem, esclarecendo que não se tratam de estágios do desenvolvimento da mente, como na teoria de Piaget, mas de estágios na relação entre o indivíduo e o conhecimento.

O primeiro estágio seria o da aprendizagem autodirigida. Desde o nascimento, a criança começaria a explorar o mundo à sua volta, tocando objetos, levando-os à boca etc., e não somente na relação entre a criança e os objetos, mas também em sua relação com as pessoas. Papert diz que os pais podem pensar que estão ensinando a criança, mas que o ensino é um fator de menor importância nesse processo e "provavelmente o bebê está aprendendo de maneira autodirigida" (Papert, 2000, parte 1). Antes de prosseguirmos nessa linha de raciocínio de Papert, cabe uma observação. Está implícita a essa afirmação feita pelo pesquisador a identificação entre aprendizagem espontânea e aprendizagem autodirigida. Contudo, mesmo admitindo-se hipoteticamente que os pais não estejam, ao contrário de suas expectativas, dirigindo a aprendizagem do bebê, isso não significará que se trata de aprendizagem autodirigida, mas sim de aprendizagem espontânea. Igualar as duas coisas é perder de vista que um processo autodirigido é um processo autoconsciente, o que obviamente não ocorre com o bebê. Não afirmamos que Papert suponha haver tal autoconsciência, mas a identificação entre aprendizagem espontânea e aprendizagem autoconsciente tem implicações na continuidade do seu raciocínio, como veremos adiante.

Retomando o pensamento de Papert, aos poucos o mundo da criança se expande e deixa de ser constituído apenas pelo que pode ser tocado diretamente por 
ela e essa expansão a leva a formular questões sobre o mundo. Para Papert, a maneira como nossa sociedade age em relação a esse momento é fazendo com que a criança passe a aprender por meio do que os adultos dizem a ela, ao invés de aprender por exploração. Esse seria o segundo estágio, cujo clímax seria atingido na escola, onde a criança para de aprender por si mesma e passa a aprender apenas o que os adultos lhe dizem, recebendo depósitos de conhecimento, num processo que cercearia a capacidade de aprender da criança. Mas como, "apesar da escola", algumas pessoas adquirem nesse segundo estágio certas habilidades, como ler e usar uma biblioteca, então elas passam a usar essas habilidades para explorar por si mesmas o mundo mais amplo que aquele com o qual têm contato imediato. Essas pessoas seriam "sobreviventes", sua capacidade de aprender de forma criativa teria sobrevivido à escola. Esse seria o terceiro estágio, no qual o adulto aprende de forma muito similar àquela da criança pequena, explorando por si mesmo o mundo. Essa forma de aprendizagem, tal como a do bebê, não seria predominantemente verbal como no segundo estágio, mas pautada principalmente pelo fazer. Papert afirma, então, que o desenvolvimento da tecnologia estaria produzindo condições que tornariam dispensável o segundo estágio. Se no passado a aquisição de conhecimento sobre o mundo mais amplo dependia do ensino, cuja forma mais extrema seria a escola, a tecnologia de informação possibilitaria a uma pessoa, na atualidade, adquirir conhecimentos que indivíduos de algumas gerações atrás só poderiam aprender mais tarde em suas vidas, tendo que lutar para sobreviver ao ensino escolar. A tecnologia de informação pouparia a criança desse processo de escolarização que é "traumático, perigoso e precário" (Papert, 2000, parte 1); permitiria às crianças "manterem a curiosidade e o sentido do poder intelectual que elas tinham quando nasceram" (idem, ibid.).

Cumpre registrar que Papert explicita no debate que adota deliberadamente um tom polêmico para tratar da relação ensino/aprendizagem. Contudo, não restam dúvidas sobre sua concepção do ensino como algo que prejudica a (suposta) aprendizagem autônoma.

A influência desse pensamento é notória na produção nacional de IE. Fagundes, Sato e Maçada (1999, p. 18) indagam: “Quando iremos nos dar conta de que o processo natural de desenvolvimento do ser humano é 'atropelado' pela escola e pelas equivocadas práticas de ensino?". As autoras apresentam uma posição contundente em termos de apreciação negativa do ensino:

Na verdade, no ensino, tudo parte das decisões do professor, e a ele, ao seu controle, deverá retornar. Como se o professor pudesse dispor de um conhecimento único e verdadeiro para ser transmitido ao estudante e só a ele coubesse decidir o que, como e com que qualidade deverá ser aprendido. Não se dá oportunidade ao aluno para qualquer escolha. Não lhe cabe tomar decisões. Espera-se sua total submissão a regras impostas pelo sistema. (p. 15-16) 
As autoras aproximam-se bastante das concepções de Papert, chegando a se referir ao processo de escolarização como "domesticação":

Se o ser humano deixa de ser uma criança perguntadora, curiosa, inventiva, confiante em sua capacidade de pensar, entusiasmado por explorações e por descobertas, persistente nas suas buscas de soluções, é porque nós, que o educamos, decidimos "domesticar" essa criança, em vez de ajudá-la a aprender, a continuar aprendendo e descobrindo. (Idem, ibid., p. 18)

A tese de que a aprendizagem deve ser algo que se dá pela iniciativa do aluno, pelas suas explorações - e não pela via da transmissão - é quase uma unanimidade na literatura de IE. A escola compatível com os tempos atuais é assim vista:

\begin{abstract}
A sala de aula deve deixar de ser o lugar das carteiras enfileiradas para se tornar um local em que professor e alunos podem realizar um trabalho diversificado em relação a conhecimento e interesse. O papel do professor deixa de ser o de "entregador" de informação para ser o de facilitador do processo de aprendizagem. $\mathrm{O}$ aluno deixa de ser passivo, de ser o receptáculo das informações, para ser ativo aprendiz, construtor do seu conhecimento. Portanto, a ênfase da educação deixa de ser a memorização da informação transmitida pelo professor e passa a ser a construção do conhecimento realizada pelo aluno de maneira significativa, sendo o professor o facilitador desse processo de construção. (Valente \& Almeida, 1997, p. 8)
\end{abstract}

Trata-se, para os autores citados, de romper com tudo aquilo que se possa identificar com a escola "tradicional": a passividade do aluno, a disposição das carteiras, a transmissão de conhecimento, etc. O ensino é identificado com a "entrega" de informações. O papel do professor é o de facilitador de um processo dirigido pelo aluno.

Cumpre registrar que há posições diferenciadas quanto ao grau de negação dos elementos associados ao "tradicional". Enquanto Fagundes, Sato e Maçada (1999) expressam uma forte rejeição ao ensino (defendendo os projetos de aprendizagem, em oposição aos de ensino) e à definição de conteúdos por parte da escola (portanto à noção de currículo), Valente (1999, p. 11) refere-se a "ensino-aprendizagem" e a "conteúdos curriculares":

O termo "Informática na Educação" que apresentamos neste livro refere-se à inserção do computador no processo de ensino-aprendizagem de conteúdos curriculares de todos os níveis e modalidades de Educação. Ao longo deste capítulo, mostramos e discutimos as vantagens e desvantagens como máquina de ensino e como auxiliar do processo de construção do conhecimento.

Contudo, a despeito dessas nuanças, é nítida a forte unidade existente na literatura de IE, em torno da inconveniência da transmissão de conhecimentos, tida como algo que não colabora com a aprendizagem (antes, cria obstáculos à sua 
realização). Os casos mais contundentes atacam a existência de um currículo, de conteúdos determinados pela escola.

Adiante faremos uma análise crítica dessas posições. Desde já, cabe afirmar que não rejeitamos a crítica feita ao ensino tradicional. Essa crítica - que vêm sendo feita desde Rousseau, passando por Pestalozzi e Froebel no século XIX (Arce, 2002) e pelo movimento escolanovista no século XX - contém aspectos de inegável pertinência. O que questionamos é que, em nome dessa crítica, se desvalorize a transmissão do conhecimento historicamente elaborado e se negue o papel da escola na seleção de conteúdos a serem ensinados.

\section{Problematizando o aprender a aprender na informática educativa}

\section{Os três estágios de Papert}

Como já apresentamos, segundo Papert (op. cit.), no primeiro estágio, não haveria ensino; a criança aprenderia por exploração do mundo, de forma autônoma, autoguiada. Contudo, há que se reconhecer que essa exploração do mundo precisa ser orientada por adultos, para uma efetiva aprendizagem e para segurança da própria criança: há experiências que a criança não pode fazer e estas lhe serão vedadas. Por exemplo, ela não poderá experimentar o gosto de produtos de limpeza ou de higiene pessoal, muito embora estes possam exercer-lhe - dado o afã de exploração sensorial do mundo ao seu alcance - atração, pelo seu aspecto (substâncias coloridas e/ou odoríferas, cremosas, entre outras); não poderá explorar pelo tato objetos em alta temperatura (a criança será mantida à distância do fogão!), tomadas e aparelhos elétricos, entre outros. Pequenos objetos devem ser mantidos a distância, dado o risco de serem introduzidos na boca ou narinas. O deslocamento da criança será limitado em função de objetos que representem risco. De outro lado, determinadas experiências serão consideradas proveitosas e serão estimuladas. Exemplificando-se: o conhecimento (pelo paladar/olfato) de bebidas e alimentos adequados àquela idade; a manipulação de massas especiais de modelar, tintas especiais, etc. Ou seja, há, sim, um processo de condução das iniciativas da criança.

Quando um adulto alimenta uma criança, por exemplo, emprega utensílios e com isso está ensinando a criança a se relacionar com esses objetos socialmente criados. Quando se comunica com a criança emprega a língua falada e isso a introduz no mundo da linguagem. $\mathrm{O}$ adulto e também as crianças mais velhas, quando realizam alguma ação voltada à criança pequena, empregam, além da língua falada, outras formas de comunicação, como a linguagem gestual e as expressões faciais, ou seja, iniciam o bebê nas formas de comunicação desenvolvidas ao longo da história humana. Em suma, desde o primeiro dia de vida de um ser humano, suas aprendizagens 
são mediadas pelas relações com as outras pessoas, como demonstra Martins (2012), apoiada nas pesquisas realizadas por Vigotski, Luria e Leontiev.

Embora Papert tome como ponto de partida o fato óbvio de que as aprendizagens realizadas pela criança nos seus primeiros anos de vida dependem, em boa medida, da relação sensorial com o mundo imediatamente à sua volta, ele extrai desse fato uma conclusão que não corresponde à realidade. Para o pesquisador, essa aprendizagem ocorreria por meio da relação direta entre a criança e o mundo com uma interferência mínima do ensino pelos adultos. Para ele, somente quando a criança passa a buscar conhecer o mundo que ela não pode tocar é que o ensino pelo adulto passa a ocupar o lugar que antes era destinado à aprendizagem espontânea, o qual, como já dissemos, ele identifica com a aprendizagem autodirigida.

Outro ponto a ser observado é que Papert parece considerar que o ensino só existiria em situação de transmissão verbal e, nesse sentido, entende que os primeiros contatos da criança com o mudo ocorrem sem a interferência do ensino. Ao que parece, ele identifica como ensino apenas uma situação na qual há uma pessoa transmitindo verbalmente uma informação à outra pessoa. Claro que a referência para a definição de ensino deve ser aquela situação social na qual ele se apresenta de forma mais nítida, mais bem delimitada. Não há dúvida de que a forma pela qual o ensino se apresenta mais nitidamente é a forma escolar, na qual há um professor transmitindo conhecimento aos seus alunos. Mas isso não quer dizer que não haja ensino em situações em que um adulto, por exemplo, impede uma criança de realizar um ato perigoso para ela, ou quando o adulto canta e bate palmas em frente à criança. A imitação é uma importante fonte de aprendizagem para a criança e, quando fazemos algo para que a ela nos imite, estamos ensinando. Há muitas formas de se ensinar e muitos níveis de consciência acerca do processo de ensino, tanto por parte de quem ensina como por parte de quem aprende. A visão de ensino e aprendizagem de Papert mostra-se bastante reducionista, o que põe em questão suas principais assertivas sobre o papel da tecnologia no desenvolvimento de aprendizagens autônomas.

No que se refere ao segundo estágio de Papert e à preconização do terceiro estágio como uma espécie de retorno ao primeiro, destaquemos que, na crítica feita à escola e aos problemas ali encontrados (unilateralidade, ênfase na retenção mecânica de conteúdos, etc.), há uma associação desses problemas com o "antigo", com o "ensino tradicional". Papert chega a defender (e a constatar) um processo que estaria levando ao desaparecimento da escola. Em seu lugar, novos espaços deveriam ser criados para, com o suporte das tecnologias da informação, garantir oportunidades para se desenvolver a aprendizagem autônoma do educando.

Embora a defesa (e/ou constatação) do fim da escola não esteja tão presente na literatura nacional de IE, podemos reconhecer elementos dessa posição de Papert na 
defesa da eliminação de tudo aquilo que se identifica com o "tradicional", o "antigo". Deve-se suprimir o ensino, dando-se lugar à aprendizagem; deve-se abandonar a tradicional disposição das carteiras; a escola deve deixar de direcionar o aluno para determinados conteúdos, já que o professor não é o "dono da verdade". Em suma, deve-se deixar de praticar o ensino para que o aluno adquira, de forma autoguiada, conhecimentos demandados pelo cotidiano, devendo o professor ser apenas um facilitador, jamais um "entregador de conhecimento".

Estas posições visam aproximar esse modelo de aprendizagem ao processo de investigação científica. Contudo, a problematização que se coloca aqui é formulada por Saviani (2008a, p. 37) nos seguintes termos: “(...) o ensino não é um processo de pesquisa. Querer transformá-lo em um processo de pesquisa é artificializá-lo". Se se trata do desvelamento do desconhecido, há que se considerar que

(...) o desconhecido só se define por confronto com o conhecido, isto é, se não se domina o já conhecido, não é possível detectar o ainda não conhecido, a fim de incorporá-lo, mediante a pesquisa, ao domínio do já conhecido (...). Qualquer pesquisador sabe que ninguém chega a ser pesquisador, a ser cientista, se ele não domina os conhecimentos já existentes na área em que ele se propõe a ser investigador, a ser cientista. (Idem, ibid., p. 38-39)

Observemos, de passagem, que essas considerações foram feitas por Saviani numa Conferência Brasileira de Educação realizada em 1980, portanto quinze anos antes desse debate entre Freire e Papert.

Na pesquisa científica, o conhecimento existente é apropriado pelo pesquisador por algum mecanismo de transmissão: os artigos científicos são essencialmente registros do conhecimento produzido, a ser transmitido à comunidade científica, que partirá desse conhecimento para superá-lo por incorporação.

Ora, diante desta constatação, é bastante problemático que uma concepção pedagógica que busque aproximar a aprendizagem do método científico pretenda abrir mão da transmissão de conhecimentos. E o resultado, já verificado a partir das experiências empreendidas pelo movimento escolanovista, não é alentador:

Com esta maneira de interpretar a educação, a Escola Nova acabou por dissolver a diferença entre pesquisa e ensino, sem se dar conta de que, assim fazendo, ao mesmo tempo que o ensino era empobrecido, inviabilizava-se também a pesquisa. (Saviani, op. cit., p. 38)

\section{Projeto de sociedade subjacente ao aprender a aprender: justificação de privilégios?}

Que projeto de sociedade orienta as pedagogias do aprender a aprender, conforme se manifestam na literatura de IE? Um trecho de Papert (1993, p. 13) nos parece bastante significativo nesse sentido: 
Hoje, nos países industrializados, a maioria das pessoas tem empregos que não existiam na época em que muitos nasceram. A habilidade mais determinante do padrão de vida de uma pessoa é a capacidade de aprender novas habilidades, assimilar novos conceitos, avaliar novas situações, lidar com o inesperado. Isso será cada vez mais verdadeiro no futuro: a habilidade para competir tornou-se a habilidade de aprender. (Grifos nossos)

Na sequência desse texto, que é o Prefácio do difundido livro A máquina das crianças, Papert (op. cit., p. 13) complementa: “O que é um truísmo para as pessoas o é mais ainda para as nações. A força competitiva de uma nação no mundo moderno é diretamente proporcional à sua capacidade para aprender".

Cabe destacar que há importantes elementos ideológicos implícitos a essas afirmações. Embora Papert não faça uma defesa clara e explícita de uma sociedade baseada na competição entre indivíduos e entre nações, ele toma esse tipo de sociedade como algo dado e não sujeito à problematização, e simplesmente afirma: "a habilidade para competir tornou-se a habilidade de aprender"; e esta é a questão determinante ao "padrão de vida de uma pessoa" (idem, ibid.).

A não necessidade de Papert explicitar - e sustentar devidamente - sua concepção de sociedade baseada na competição provém do fato de que esta concepção faz parte de um ideário bastante arraigado no senso comum dos indivíduos, na fase atual do capitalismo, denominada, de forma problemática, de era da globalização. Há, portanto, uma compreensão de sua parte de que, para o futuro, a única realidade social possível é a perpetuação do modelo atual, baseado nas formas mais exacerbadas de competição.

Ora, a sociedade atual, fundada na competição, está longe de ser a melhor sociedade que o gênero humano, em seu processo histórico, seja capaz de construir. A afirmação de Papert se harmoniza com a tese fatalista do fim da história, propalada especialmente nos anos de 1990, após a Queda do Muro de Berlim, tese refutada por Hobsbawm (1995, p. 16), que afirma: “A única generalização cem por cento segura sobre a história é aquela que diz que enquanto houver raça humana haverá história".

Quando a educação, a despeito dos apelos à criatividade e à autonomia de pensamento, volta-se à formação de indivíduos competitivos para uma sociedade competitiva, tal como na concepção educacional preconizada por Papert, o que resulta dessa educação é o reforço a uma ideologia que dá suporte às relações de dominação próprias ao capitalismo.

Cabe também chamar a atenção para o fato de que a proposta de preparar alunos competitivos contém uma problemática premissa nuclear, pois a noção de vencedor - própria da lógica da competição - pressupõe a existência de perdedores, e é exatamente isso que a história dos últimos séculos tem demonstrado. 


\title{
Problemas com a imprecisa caracterização do ensino tradicional
}

São muito comuns na literatura de IE as referências críticas ao "ensino tradicional", fazendo-se um contraponto deste com as possibilidades abertas pelas novas tecnologias. A tônica dominante dessas análises é: a inserção das novas tecnologias deve ser acompanhada de profundas mudanças pedagógicas, que rompam com a ultrapassada lógica da transmissão e desloquem a ênfase para a construção do conhecimento, sob o risco de se incorrer nas velhas práticas, apenas com ferramentas novas. O trecho a seguir ilustra essa posição:

\begin{abstract}
A abordagem que usa o computador como meio para transmitir a informação ao aluno mantém a prática pedagógica vigente. Na verdade, a máquina está sendo usada para informatizar os processos de ensino existentes. Isso tem facilitado a implantação do computador nas escolas, pois não quebra a dinâmica tradicional já adotada. (Valente, 1999, p. 12)
\end{abstract}

Na maior parte dos casos, porém, não é apresentada uma análise histórica e teoricamente bem fundamentada do que seja uma educação "tradicional". Há uma aceitação tácita de que o que é praticado majoritariamente nas escolas é o ensino tradicional, ultrapassado, arcaico, com remotas origens. E se há também um consenso bastante estabelecido em torno da má qualidade da educação oferecida nas escolas brasileiras, em especial nas escolas públicas, segue-se com facilidade uma condenação, no conjunto, ao "tradicional" e, em casos extremos, a tudo aquilo que possa se associado a ele: currículos, organização de séries por idade, com conteúdos pré-estabelecidos, disposição das carteiras, papel do professor como transmissor de conhecimentos, avaliação dos conteúdos aprendidos, etc. Não é a toa que Papert (no debate já citado com Paulo Freire) chega a constatar e defender o fim da escola.

Entretanto, uma análise que situe historicamente a educação tradicional vai além desse estereótipo e procura compreender os aspectos positivos e negativos dentro do contexto no qual se desenvolveu essa pedagogia. Nesse sentido, entendemos que a área de IE poderia avançar em direção a uma crítica mais consistente à escola tradicional, se levasse em consideração estudos que não são recentes, mas que não se fazem presentes entre as referências citadas pela área, como Snyders (1974) e Gramsci (1982).

Apoiando-se tanto em Gramsci como em Snyders, Saviani (2008a) formulou sua própria análise histórica da escola tradicional, na forma de três teses diametralmente contrapostas a ideias largamente difundidas pelo ideário escolanovista. A primeira dessas ideias é a de que a escola nova seria revolucionária e a escola tradicional, conservadora. Em oposição a essa ideia, Saviani argumenta que a escola tradicional caracterizou-se historicamente como o tipo de escola defendido pela 
burguesia, quando esta desempenhou o papel de classe revolucionária na luta contra o modo de produção feudal. O tipo de escola defendido pelo movimento escolanovista situou-se, por outro lado, num momento histórico em que a burguesia já não desempenhava o papel de classe revolucionária; muito pelo contrário, lutava, na condição de classe dominante, contra a classe revolucionária, ou seja, contra os trabalhadores.

A segunda ideia polemizada por Saviani em seu mencionado texto foi a de que o método pedagógico preconizado pela escola nova seria científico, ao passo que a escola tradicional representaria um pensamento pré-científico. Em oposição a essa ideia, Saviani argumenta que, historicamente, o método de ensino tradicional estaria vinculado ao método da ciência moderna, aquela mesma ciência que possibilitou a Revolução Industrial, sendo, portanto, descabida a acusação escolanovista de que a escola tradicional seria medieval e pré-científica. A diferença entre as duas, argumenta Saviani, no que se refere às relações entre o método pedagógico e o método científico, está no fato de que a escola tradicional centrava seu método na transmissão do produto do pensamento científico, ao passo que a escola nova centrava seu método no processo de aquisição de novos conhecimentos; confundia ensino com pesquisa, não diferenciando aquilo que é desconhecido pelo indivíduo daquilo que é desconhecido pela sociedade. A verdadeira pesquisa científica é aquela que avança no que é desconhecido pela sociedade e isso só pode ser realizado por pessoas que dominam aquilo que já é socialmente conhecido. Ao desconsiderar a importância da transmissão do conhecimento científico já existente, a escola nova estaria colocando-se numa posição não científica, ao contrário do que seus defensores alegavam.

A terceira ideia bastante difundida pelos escolanovistas era a de que a escola nova seria democrática, ao passo que a escola tradicional seria autoritária, antidemocrática. Em relação a essa ideia, a tese de Saviani é uma consequência das teses anteriores: ao preconizar a difusão do conhecimento já existente, a escola tradicional teria sido mais democrática, apesar de adotar procedimentos e normas disciplinares apontados como autoritários. Já a escola nova, a despeito de adotar formas de relacionamento entre professores e alunos aparentemente democráticas, teria sido antidemocrática ao negar-se a transmitir aos alunos o conhecimento já existente.

Nem Snyders, nem Gramsci ou Saviani pretenderam, com suas reflexões, defender a escola tradicional como a alternativa educacional adequada a uma perspectiva crítica em relação à sociedade capitalista. Coerentemente com a categoria de historicidade, tão cara ao marxismo, seus argumentos pretenderam simplesmente superar as visões estigmatizantes da escola tradicional e situá-la no movimento da história, o qual aponta para a necessidade da superação tanto da escola tradicional, como das pedagogias do aprender a aprender. 
Torna-se, portanto, bastante simplista a identificação direta e mecânica entre a escola tradicional e os males da educação brasileira. É necessário reconhecer que, se as práticas educativas guardam ainda forte relação como a pedagogia tradicional, esta concepção pedagógica se faz presente em formas bastante degradadas, tendo-se em vista as conhecidas insuficiências das escolas, em termos de infraestrutura, tamanho das turmas, formação e remuneração dos professores, entre outros conhecidos problemas. Como o professor - que, do ponto de vista da escola tradicional, estaria no centro do processo, sendo o transmissor do conhecimento - poderia exercer o papel a ele reservado em condições reconhecidamente aviltantes?

Acresce que, se as concepções tradicionais ainda estão muito presentes na escola, há igualmente uma ampla assimilação de valores de outras concepções pedagógicas como o próprio escolanovismo (aprender a aprender) e o tecnicismo (ênfase da eficiência do processo), havendo não uma única concepção dominante, mas um amálgama de várias concepções que exercem diferentes graus de influência em diferentes espaços pedagógicos. Saviani (2008b) caracteriza como neoprodutivismo as tendências pedagógicas hegemônicas a partir da década de 1990, com as variantes neoescolanovismo, neoconstrutivismo e neotecnicismo.

Entendemos que os deslocamentos e equívocos com relação ao que significa a concepção pedagógica tradicional e sua real presença na educação brasileira dificultam o diagnóstico correto da realidade, prejudicando a discussão sobre as possibilidades de solução de seus problemas, incluindo-se aí a discussão sobre os usos das novas tecnologias.

\section{A falsa contraposição entre transmissão e construção de conhecimento}

Como já mencionado, as pedagogias do aprender a aprender estabelecem uma hierarquia valorativa entre o aprendizado que o indivíduo realiza por si mesmo e aquele onde está presente a transmissão por outra pessoa (Duarte, 2001). Em outras palavras, para essas pedagogias, os conhecimentos adquiridos espontaneamente pelo aluno são mais importantes do que aqueles que lhe são transmitidos.

Em certas produções, ocorre até mesmo uma desvinculação tácita entre transmissão e conhecimento. Valente (1999, p. 12), por exemplo, afirma: "A atividade de uso do computador pode ser feita tanto para continuar transmitindo a informação para o aluno e, portanto, para reforçar o processo instrucionista, quanto para criar condições de o aluno construir seu conhecimento".

Ou seja, Valente vincula transmissão a informação, e aprendizagem a conhecimento. Essa associação aparece ao longo do artigo e em outros escritos seus. Ao que parece, 
o autor considera que só se pode adquirir conhecimento em um processo autônomo de construção e que, pela via da transmissão, só é possível adquirir informações.

Embora concordemos que há uma diferença entre conhecimento e informação, nossa visão é oposta à desse autor; entendemos que a escola precisa transmitir sistematicamente, pelo ensino, os conhecimentos, ao passo que as informações podem ser obtidas pelos alunos sem a mediação do professor. Como explica Saviani (2011, p. 309):

\begin{abstract}
Na verdade, parece que a denominação de "sociedade do conhecimento" não é apropriada para caracterizar a época atual. Melhor seria, talvez, falar-se em "sociedade da informação". Isso porque conhecimento implica a capacidade de compreender as conexões entre os fenômenos, captar o significado das coisas, do mundo em que vivemos. E hoje parece que quanto mais informações circulam de forma fragmentada pelos mais diferentes veículos de comunicação, mais difícil se torna o acesso ao conhecimento que nos permitiria compreender o significado da situação em que vivemos.
\end{abstract}

Um aspecto que parece estar ausente dessas concepções que contrapõem aprendizagem (ou construção do conhecimento) a ensino é o fato de que o conhecimento acumulado pela humanidade não é um amontoado desconexo de informações isoladas, mas sim uma condensação de atividade. Quando o indivíduo é levado, pelo ensino, a realizar uma atividade mental em relação a esse conhecimento socialmente existente, ele se apropria da atividade intelectual acumulada e estruturada no conhecimento que esteja sendo objeto do trabalho educativo. Para que o ensino alcance sua finalidade, é preciso que a aprendizagem ocorra e, para que isso aconteça, é necessário que o aluno reproduza, por sua atividade intelectual, a essência da atividade intelectual acumulada no conhecimento que lhe está sendo transmitido. Esse é um aspecto importante que põe por terra a ideia de que alguém se relacione com o mundo de maneira direta. A rigor, não existe relação entre um indivíduo e a sociedade que não seja mediada por alguma forma de atividade de outros seres humanos. Sempre estamos aprendendo com as outras pessoas, seja na forma de um ensino direto e deliberado, seja na forma indireta ou talvez até involuntária. De qualquer modo, o mundo à nossa volta é repleto de atividade objetivada, o que por si só estabelece que a transmissão da cultura é condição indispensável à vida propriamente humana. Como afirma o psicólogo Leontiev (1978, p. 272),

As aquisições do desenvolvimento histórico das aptidões humanas não são simplesmente dadas aos homens nos fenômenos objetivos da cultura material e espiritual que as encarnam, mas são aí apenas postas. Para se apropriar destes resultados, para fazer deles as suas aptidões, "os órgãos da sua individualidade", a criança, o ser humano, deve entrar em relação com os fenômenos do mundo circundante através doutros homens, isto é, num processo de comunicação com eles. Assim, a criança aprende a atividade adequada. Pela sua função, este processo é, portanto, um processo de educação. (Destaques no original) 
Papert (op. cit.) está correto ao afirmar que a escola é a forma de educação na qual o ensino aparece de maneira mais explícita e intensificada. Mas, ao contrário dele, entendemos que isso faz da escola uma forma de educação indispensável ao pleno desenvolvimento da capacidade de aprendizagem e da criatividade humana.

\section{Considerações finais: superação por incorporação}

Uma geração só pode superar a anterior por incorporação do acervo de conhecimentos acumulados. Assim, sustentamos que a transmissão de conhecimentos é elemento indispensável para a construção de novos conhecimentos; que a heteronomia é elemento de superação da anomia, em direção à autonomia.

É legítima a crítica feita pelas pedagogias do aprender a aprender à memorização mecânica de conteúdos estáticos, que acaba por obscurecer o necessário desvelamento da realidade e valorizar um "conhecimento ornamental" e um verbalismo que pouco contribuem para a emancipação do aluno. Porém, entendemos que não é se desvalorizando a transmissão de conhecimento, ou até mesmo negando sua possibilidade, que se estará avançando. Antes, tal postura leva a uma regressão, como mostram as já citadas análises históricas. Embora concordemos que "pode haver ensino sem haver aprendizagem" (Fagundes, Sato \& Maçada, 1999, p. 16), entendemos que entre esta afirmação e a oposição entre ensino e aprendizagem há uma grande distância.

Para a pedagogia histórico-crítica, a superação da transmissão de conhecimentos estáticos se alcança pela transmissão de conhecimentos nas suas formas mais desenvolvidas, que não envolvem apenas fatos ou informações, mas também processos, conceitos e suas interrelações. A noção de conhecimento em suas formas mais desenvolvidas (mais ricas, mais elaboradas) decorre da concepção dialética da produção do conhecimento, segundo a qual novos conhecimentos se afirmam não por pura e simples negação do conhecimento anteriormente vigente, mas em um processo de superação por incorporação. Assim, essa noção exige que se busque identificar a riqueza de atividades humanas presentes em determinado conteúdo cultural, incluindo-se aí as diversidades de concepções que podem ser consideradas legítimas na apreciação de certo objeto.

Portanto, a escola não pode abrir mão de seu papel de selecionar os conteúdos mais importantes, com maior nível de desenvolvimento, e buscar os melhores meios para viabilizar sua apropriação por parte do educando, sob o risco de contribuir cada vez mais para o reconhecido nível de deterioração da educação em nosso país, nos dias atuais. Papel que - cumpre enfatizar - cabe primordialmente à 
educação formal, à escola, que se afirmou historicamente como a forma dominante de educação humana; consequentemente, papel que nenhuma outra instância social cumprirá.

\section{Referências}

ARCE, A. A pedagogia na "era das revoluções": uma análise do pensamento de Pestalozzi e Froebel. Campinas: Autores Associados, 2002.

DUARTE, N. Concepções afirmativas e negativas sobre o ato de ensinar. Cadernos Cedes, Campinas, v. 19, n. 44, p. 85-106, 1998.

DUARTE, N. As pedagogias do "aprender a aprender" e algumas ilusões da assim chamada sociedade do conhecimento. Revista Brasileira de Educação, Rio de Janeiro, n. 18, p. 35-40, set/dez. 2001.

FAGUNDES, L.C; SATO, L.S; MAÇADA, D.L. Aprendizes do futuro: as inovações começaram. Brasília, DF: MEC/Seed, Proinfo, 1999. 95p.

FREIRE, P.; PAPERT, S. O futuro da escola e o impacto dos novos meios de comunicação no modelo de escola atual. Produtor: Márcia Moreno e Marco Aurélio Del Rosso. TV PUC de São Paulo com apoio do Jornal Data. nov. 1995. Disponível em: <http:// www.paulofreire.ce.ufpb.br/paulofreire/Controle?op=detalhe\&tipo=Video\&id=37>. Acesso em: 2 mar. 2012.

GRAMSCI, A. Para a investigação do princípio educativo. In: GRAMSCI, A. Os intelectuais e a organização da cultura. 4. ed. Rio de Janeiro: Civilização Brasileira, 1982. p. 129-139.

HOBSBAWM, E. A era dos extremos: o breve século XX: 1914-1991. São Paulo: Cia das Letras, 1995.

LEONTIEV, A. O desenvolvimento do psiquismo. Lisboa: Livros Horizonte, 1978.

MARTINS, L.M. O desenvolvimento do psiquismo e a educação escolar: contribuições à luz da psicologia histórico-cultural e da pedagogia histórico-crítica. 2012. 250f. Tese (Livre-Docência em Psicologia da Educação) - Faculdade de Ciências, Universidade Estadual Paulista "Júlio de Mesquita Filho", Bauru.

PAPERT, S. Constructionism versus instructionism. 1980. Disponível em: <http://www. papert.org/articles/const_inst/const_inst1.html>. Acesso em: 2 mar. 2012.

PAPERT, S. A máquina das crianças - repensando a escola na era da informática. Ed. rev. Porto Alegre: Artmed, 1993. 220p. 
PAPERT, S. The future of school; discussion between Seymour Papert and the Brazilian philosopher and educator Paulo Freire. 2000. Disponível em: <http://www.papert. org/articles/freire/freirePart1.html>. Acesso em: 2 mar. 2012.

SAVIANI, D. Pedagogia histórico-crítica. 9. ed. Campinas: Autores Associados, 2005.

SAVIANI, D. Perspectiva marxiana do problema da subjetividade-intersubjetividade. In: DUARTE, N. (Org.). Crítica ao fetichismo da individualidade. Campinas: Autores Associados, 2006. p. 21-52.

SAVIANI, D. Educação: do senso comum à consciência filosófica. 17. ed. Campinas: Autores Associados, 2007.

SAVIANI, D. Escola e democracia. Campinas: Autores Associados, 2008a.

SAVIANI, D. História das ideias pedagógicas no Brasil. 2. ed. Campinas: Autores Associados, 2008b.

SAVIANI, D. Analfabetismo no Brasil e no mundo. Entrevista concedida à revista TIC Educação, 10 set. 2010. In: SAVIANI, D. Educação em diálogo. Campinas: Autores Associados, 2011. p. 307-309. Disponível em: <http://www.odisseu.com/TicEducacao/Newsletter/120_13setembro2010/index.html>. Acesso em: 3 mar. 2012.

SNYDERS, G. A educação tradicional. In: SNYDERS, G. Pedagogia progressista. Coimbra: Almedina, 1974. p. 13-48.

VALENTE, J.A. Diferentes usos do computador na educação. In: VALENTE, J.A. Computadores e conhecimento: repensando a educação. 1995. p. 1-28. Disponível em: $<$ http://pan.nied.unicamp.br/publicacoes/publicacao_detalhes.php?id=50> Acesso em: 15 nov. 2011.

VALENTE, J.A. Informática na educação no Brasil: análise e contextualização histórica. In: VALENTE, J.A. (Org.). O computador na sociedade do conhecimento. Campinas: Unicamp/Nied, 1999. p. 1-13.

VALENTE, J.A.; ALMEIDA, F.J. Visão analítica da informática na educação no Brasil: a questão da formação do professor. Revista Brasileira de Informática Educativa [online], Florianópolis, n. 1, p. 1-28, nov. 1997.

Recebido em 3 de abril de 2012

Aprovado em 17 de outubro de 2012. 